\title{
DEVELOPMENT OF A VARIETIAL SCREENING PROCEDURE FOR SALT TOLERANCE OF RICE (Oryza sativa L.) VARIETIES AT GERMINATION STAGE
}

\author{
P. K. Dissanayake ${ }^{1}$ and A.W. Wijeratne ${ }^{2}$
}

\begin{abstract}
Germination rates were studied using four salt tolerant varieties (At 95-26-4, At 401, Pokkali, Bw 400), one with unknown reaction to salinity (Bg352) and two salt susceptible varieties (Bg 94-1, Bg 350). In the experiment hundred seeds from each of the above varieties were placed in each Petri dish of different salt concentrations (pre test; $0 \mathrm{ds} / \mathrm{m}, 10 \mathrm{ds} / \mathrm{m}, 20 \mathrm{ds} / \mathrm{m}, 30 \mathrm{ds} / \mathrm{m}$ and in the experiment; $0 \mathrm{ds} / \mathrm{m}, 18 \mathrm{ds} / \mathrm{m}, 21$ $d s / m, 24 d s / m, 27 d s / m)$. The pre test was conducted to find out the effective range of salt concentration for the test.

There were no significant differences in germination rate among the varieties until $20 \mathrm{ds} / \mathrm{m}$ salt concentration. Germination rates of all the varieties at 30ds/m salt level were significantly suppressed compared to lower salt level. Salinity tolerant varieties maintained high germination rate up to the level of salt at $21 \mathrm{ds} / \mathrm{m}$, whereas salinity susceptible varieties maintained only up to $20 \mathrm{ds} / \mathrm{m}$. The results of this study indicated that the rate of seed germination of salinity susceptible varieties were significantly different from salinity tolerant varieties at $21 \mathrm{ds} / \mathrm{m}$ salt level. Results emphasized that the salt concentration of $21 \mathrm{ds} / \mathrm{m}$ can be used as a tool to distinguish between susceptible and resistance rice varieties at the seedling stage by comparing germination rate.
\end{abstract}

Key Words: Salt tolerance varieties, Salinity tolerance, Germination rate

\section{INTRODUCTION}

Rice (Oryza sativa L.) is a semi aquatic cereal, which is originated in the tropics. It is the primary staple food for more than two billion people in Asia, the world's most densely populated region, and for hundreds of millions of people in Africa and Latin America (IRRI, 1985).

Because of the large number of people is sustained by rice, world rice requirement is estimated to increase at the compound rate of $1.7 \%$ per year (Akbar and Ponnamperuma, 1982). In Sri Lanka, the annual natural increase of population is about $1.7 \%$ (Central Bank, 2000). But, the rice production rates are insufficient to abreast of such a population growth.

The two obvious ways of increasing rice production is extending cultivated area and increasing productivity of unit land area. But, both of these factors face number of constraints. One of the major constraints and the commonest and most extensive soil problems in the world is salinity (IRRI, 1975; Ponnamperuma, 1977; Chandler, 1979 and Akbar And Ponnamperuma, 1982, Scardaci et al.2002 ). It is estimated that, over 150 million hectares of current and potential rice land in the tropics and sub tropics are affected by salinity (Massoud, 1974). Gunadasa (1990) reported that the inland and

${ }^{1}$ Department of, Export Agriculture, Faculty of Agricultural Sciences, Sabaragamuwa University of 63 Sri Lanka, Belihuloya, 70140, Sri Lanka

${ }^{2}$ Department of, Agribusiness Management, Faculty of Agricultural Sciences, Sabaragamuwa University of Sri Lanka, belihuloya, 70140, Sri Lanka 
coastal salinity is one of the major constraints to the delivery of the full potential of rice yields of new varieties in certain areas of Sri Lanka. Gangodawila (1990), reported that about 0.7 million hectares of land area in Sri Lanka are with saline/ sodic (alkalinity) limitations, of which $18,000-45,000$ hectares of land is subjected to inland salinity (Gangodawila, 1994). The newly irrigated land areas which are under major irrigation programs in the Dry Zone are identified as those with potential for future saline/ sodic limitations (Gangodawila, 1990).

Hence it is an advantage to grow high yielding rice varieties with greater tolerance to salinity in saline and potential saline lands to offer the undiminished demand of rice. To develop high yielding varieties with high salinity tolerance, it is important to have an accurate and precise identification procedure to select best saline tolerant varieties. In the past, different screening methods have been developed to differentiate salinity tolerance rice varieties from susceptible varieties at different growth stages under field and green house conditions Ponnamperuma, 1977; Jenings et al., 1979; IRRI, 1989 and Chowdhury and Bowling, 1995). As all methods that developed for evaluation of salinity tolerance rice varieties are more time consuming, it will be more beneficial, if a proper laboratory screening procedure is developed to screen rice at seed germination and early growth stages which would save time, labour and high cost of field and greenhouse screening. In this study, germination rate of rice varieties were considered at different salt concentration levels to develop a varietal screening procedure for salt tolerance of rice varieties.

\section{MATERIALS AND METHODS}

Seven rice varieties were used in the experiments of which At 401, At 9526-4, Pokkali and Bw 400 were resistant varieties, $\mathrm{Bg} 352$ with unknown reaction to salinity and $\mathrm{Bg}$ 94-1, Bg 350 were susceptible varieties. Seeds of susceptible varieties (Bg 350, Bg 94-1) were obtained from the RRDI, Batalagoda. Seeds of resistant varieties At 401, At 95-26-4, Pokkali were from Rice Research Station, Ambalanthota. Seeds of Bw400 were from Regional Agriculture Research and Development centre, Bombuwela. Detailed descriptions of the varieties used in the study are presented in Table 01. Common salt $(\mathrm{NaCl})$, dissolved in deionized water was used to prepare salt solutions with different concentrations.

The experiment was conducted using 5 levels of salinity. Salinity levels were $0 \mathrm{ds} / \mathrm{m}, 18 \mathrm{ds} / \mathrm{m}, 21 \mathrm{ds} / \mathrm{m}, 24 \mathrm{ds} / \mathrm{m}$ and 27 $\mathrm{ds} / \mathrm{m}$ and were identified by the electrical conductivity (EC) of each saline solution. The level $0 \mathrm{ds} / \mathrm{m}$ was used as the control that contained only de-ionised water. This range of salt levels was used on the basis of pre test that had been conducted prior to the experiment using four salt levels such as $0 \mathrm{ds} / \mathrm{m}, 10 \mathrm{ds} / \mathrm{m}, 20 \mathrm{ds} / \mathrm{m}, 30 \mathrm{ds} / \mathrm{m}$. Only the fully filled good quality seeds were selected in order to minimize any unpredictable variation in seed germination. Experiment was conducted in two replicates. One hundred seeds were placed in each Petri dish lined with one piece of blotting paper at the bottom. To soak the seeds, $20 \mathrm{ml}$ of particular salt solution was added to each Petri dish. Seeds were soaked overnight and excess solution was removed to remain $7 \mathrm{ml}$ of solution that just allowed facilitating air towards seeds. To 
maintain the initial solution level of concentration $7 \mathrm{ml}$ deionised water was added daily to each Petri dish. The average temperature in the laboratory during the experiment period was $27^{\circ} \mathrm{C}$. Number of germinated seeds in each dish was counted daily after completion of soaking till 20 days. A seed was considered to have germinated either plumule or radicle had emerged.

Table 01: Rice varieties used in the study and their descriptions

\begin{tabular}{ll}
\hline VARIETY & DESCRIPTION \\
\hline Pokkali & $\begin{array}{l}\text { Low yielding, red pericarped, traditional variety in } 4 \text { month age class, } \\
\text { tolerant to salinity }\end{array}$ \\
At 95-26-4 & $\begin{array}{l}\text { High yielding, red pericarped, improved variety in } 4 \text { month age class } \\
\text { with moderately tolerant to salinity }\end{array}$ \\
At 401 & $\begin{array}{l}\text { High yielding, red pericarped, short and improved variety in } 4 \text { month age } \\
\text { class, tolerant to salinity }\end{array}$ \\
Bw 400 & $\begin{array}{l}\text { High yielding, red pericarped, short and improved variety in } 4 \text { month age } \\
\text { class with moderately tolerant to salinity }\end{array}$ \\
Bg352 & $\begin{array}{l}\text { High yielding, white pericarped, short and improved variety in } 31 / 2 \\
\text { month age class, Unknown reaction to salinity }\end{array}$ \\
Bg 94-1 & $\begin{array}{l}\text { High yielding, white pericarped, short and improved variety in } 31 / 2 \\
\text { month age class , susceptible to salinity }\end{array}$ \\
Bg 350 & $\begin{array}{l}\text { High yielding, red pericarped, short and improved variety in } 31 / 2 \text { month } \\
\text { age class, susceptible to salinity }\end{array}$ \\
\hline
\end{tabular}

\section{Analysis of Data}

The seed germination was counted from completion of soaking to 20 days after soaking in water. Seed germination of each combination in pre test was plotted against time to compare increasing trends of seed germination between varieties under different levels of salinity (Figure 01). Based on the visual observation of comparison of plotted graphs, relevant salinity levels were selected for the experiment. For the screening procedure, salinity level of $0 \mathrm{ds} / \mathrm{m}$, $18 \mathrm{ds} / \mathrm{m}, 21 \mathrm{ds} / \mathrm{m}, 24 \mathrm{ds} / \mathrm{m}$ and $27 \mathrm{ds} / \mathrm{m}$ were used.

The $\mathrm{X}, \mathrm{Y}(\mathrm{X}=$ number of days after soaking, $\mathrm{Y}=$ germination percentage) scatter plots of data were visually observed to guess the best suited model for data. Then the germination percentage of each variety was regressed against time (days after soaking) to observe the response of each variety for different levels of salt concentrations. Two regression models were employed for data according to scatter plots; Lin-log model and linear model.

Lin-log model: $\hat{Y}=\beta_{0}+\beta_{1} \log (X)$

Linear model: $\hat{Y}=\beta_{0}+\beta_{1} X$

Where $\hat{\mathrm{Y}}=$ germination percentage, $\beta_{0}$ $=$ constant, $\beta_{I}=$ regression coefficient, $X=$ days after overnight soaking in water.

Lin-log model was employed for the entire data range of $X$ while the linear model was used only for initial six days as data of all verities produced best linear fit around 6 days after soaking. This was determined by visual observations, $\mathrm{r}^{2}$ and lack-of-fit of models. For all linear regression 
models $\beta_{0}$ s were not significant. Then regression through origin model was employed for data;

$\hat{Y}=\beta_{1} X$

The analysis variance (ANOVA) procedure was carried out for each linear regression model (regression through origin model) and the $95 \%$ of prediction intervals were calculated for predicted germination percentage of each variety under different salt concentrations.

Predicted interval $=\hat{Y} \pm t_{(\alpha, \text { edf })} \operatorname{Se}(\hat{Y})$

$S e(\hat{Y})=S \sqrt{ }\left(1 / n+\left(X_{i}-\bar{X}\right)^{2} / S_{x x}\right)$

Where $\hat{Y}=$ predicted germination percentage, $\mathrm{t}_{(\alpha, \text { edf })}=$ critical $\mathrm{t}$ value at $\alpha$ $=0.05$ and edf=error degrees of freedom, $S=$ mean error sums of square, $n=$ number of observations, $\mathrm{X}_{\mathrm{i}}$ $=\mathrm{i}^{\text {th }}$ day, $\bar{X}=$ mean of $X, S_{x x}=$ sums of square of $X$.

The predicted intervals of germination percentages of each variety at different salt concentration levels were examined to identify the response of each variety for the given salt concentration level. According to differential calculus, rate of germination of seeds were taken by $\beta_{1} /$ $X$ for Lin-log model and $\beta_{l}$ for linear model.

\section{RESULTS AND DISCUSSION}

All the varieties used showed no significant differences in increasing the seed germination percentage with time upto $20 \mathrm{ds} / \mathrm{m}$ salinity level in pre test (Figure 01). The results of the present study showed some variation with the results of Pearson et al (1996) who reported that germination percentage is maintained at $80-100 \%$ even at saline solutions with EC of $25 \mathrm{ds} / \mathrm{m}-30 \mathrm{ds} / \mathrm{m}$ at $25^{\circ} \mathrm{C}$. Our results showed that the seed germination of all the varieties was drastically reduced at $30 \mathrm{ds} / \mathrm{m}$ at $25^{\circ} \mathrm{C}$ (Figure 01). At the salt concentration of $30 \mathrm{ds} / \mathrm{m}$ all the varieties delayed in the initiation of germination which is in agreement with those of Akbar and Ponnamperuma (1982) who reported that time taken for start germination was increased with increase in salt concentration, because it is directly related to the amount of water absorbed by the seed.

There were no comparable differences in germination rate at $20 \mathrm{ds} / \mathrm{m}$ and at $30 \mathrm{ds} / \mathrm{m}$ salt levels at $27^{\mathrm{O}} \mathrm{C}$ among susceptible and resistant varieties in pre test. But it showed highly significant low rate of germination at $30 \mathrm{ds} / \mathrm{m}$ salt level compared to the $20 \mathrm{ds} / \mathrm{m}$ salt level. Therefore, the experiment was conducted using smaller increments of the concentrations between $18 \mathrm{ds} / \mathrm{m}$ and 27 $\mathrm{ds} / \mathrm{m}(0,18,21,24$ and $27 \mathrm{ds} / \mathrm{m})$ to find out more precise salt level in which salinity tolerant and salinity susceptible varieties behave differently in germination rate.

Figure 02 presents Lin-log regression plots of the germination percentage of AT-95-26-4, At 401, Pokkali and Bw 400 (tolerant varieties for salinity) at different salt concentrations $(0,18,21$, 24 and $27 \mathrm{ds} / \mathrm{m})$. It showed more or less similar response of germination rate at salt concentrations of $0 \mathrm{ds} / \mathrm{m}, 18 \mathrm{ds} / \mathrm{m}$ and $21 \mathrm{ds} / \mathrm{m}$, whereas there was a remarkable gap in the regression lines at $24 \mathrm{ds} / \mathrm{m}$ and $27 \mathrm{ds} / \mathrm{m}$ concentrations compared to $0 \mathrm{ds} / \mathrm{m}, 18 \mathrm{ds} / \mathrm{m}$ and $21 \mathrm{ds} / \mathrm{m}$ salt levels. 

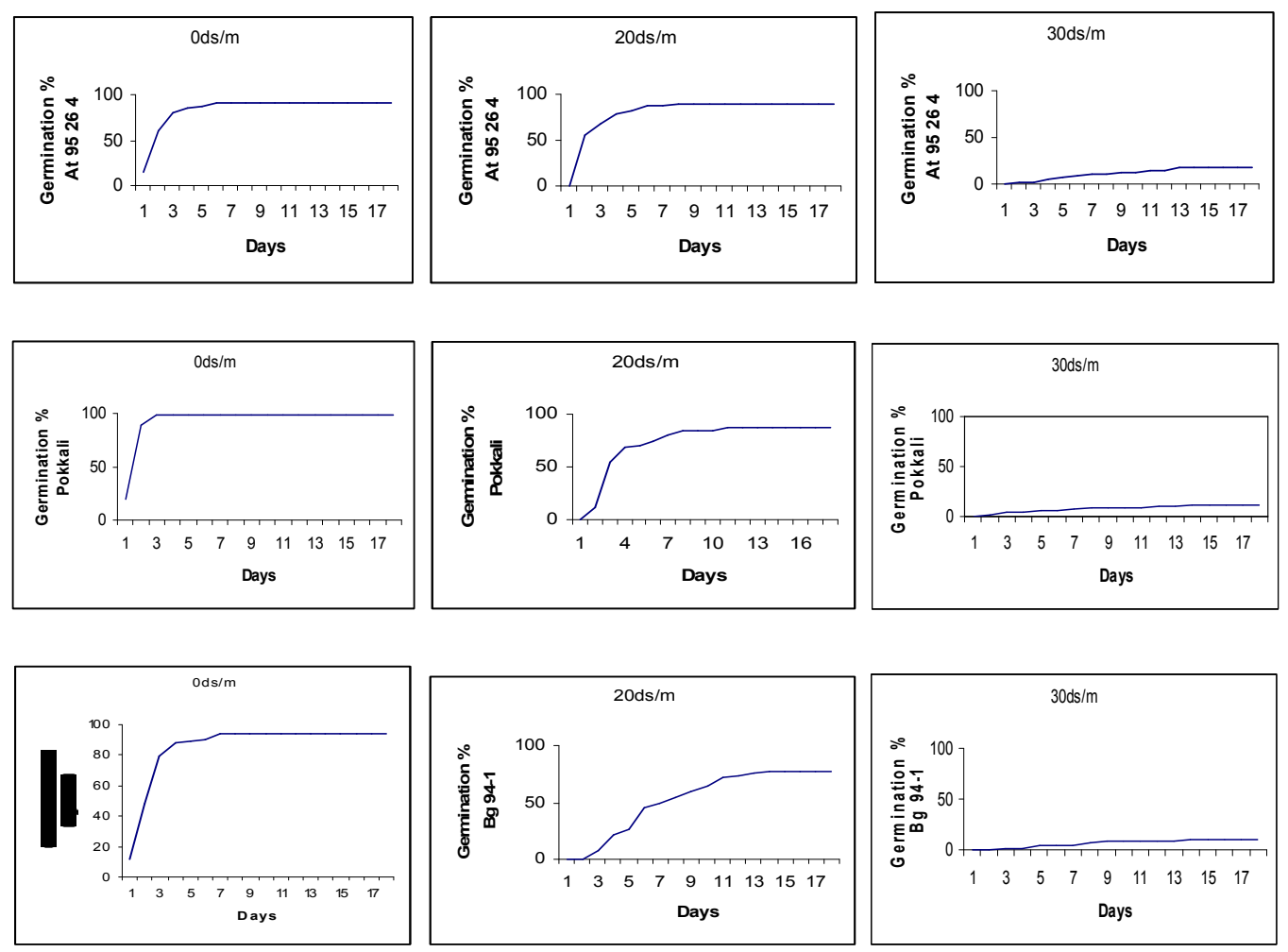

Figure 01: Behavior of Germination percentages of Salinity tolerant varieties (At 95264 and Pokkali) and a Salinity susceptible variety (Bg 94-1) at 0, 20 and $30 \mathrm{~d} / \mathrm{m}$ salt concentrations over time.

Responses of germination percentage of salinity susceptible varieties to different concentrations of salts $(0,18$, 21,24 and $27 \mathrm{ds} / \mathrm{m}$ ) are presented in Figure 03 as Lin-log regression plots. These showed that the rate of germination of these two varieties at $0 \mathrm{ds} / \mathrm{m}$ and $18 \mathrm{ds} / \mathrm{m}$ salt levels were in similar position as tolerant varieties (regression coefficients were 20.9 and 27.4 in $\mathrm{Bg} 94-1$ and 22.0 and 31.5 in Bg 350 respectively). But germination rate of susceptible varieties at $21 \mathrm{ds} / \mathrm{m}$ was significantly different from the $0 \mathrm{ds} / \mathrm{m}$ and $18 \mathrm{ds} / \mathrm{m}$ salt levels, whereas in tolerant varieties it was not. In all the varieties rate of seed germination was hindered with the increase of salinity levels. Rate and the maximum percentage of seed germination of susceptible varieties remarkably reduced than that of tolerant varieties at $21 \mathrm{ds} / \mathrm{m}$ where the tolerant varieties maintained their high level of germination. Therefore comparison of seed germination rate of susceptible and tolerant varieties at $21 \mathrm{ds} / \mathrm{m}$ could be used as a tool to differentiate salinity susceptible and salinity tolerant rice varieties. 


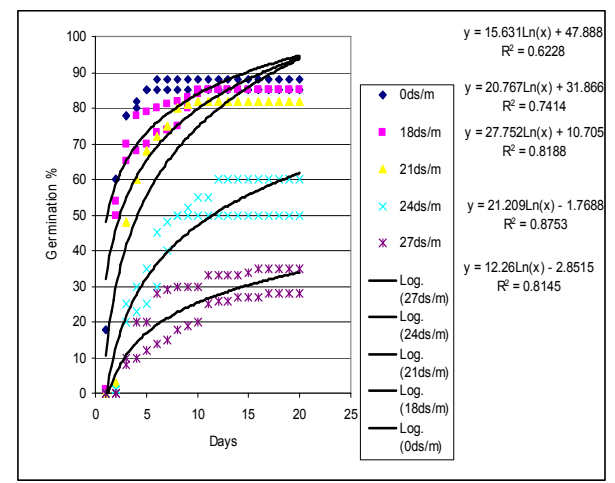

AT-95-26-4

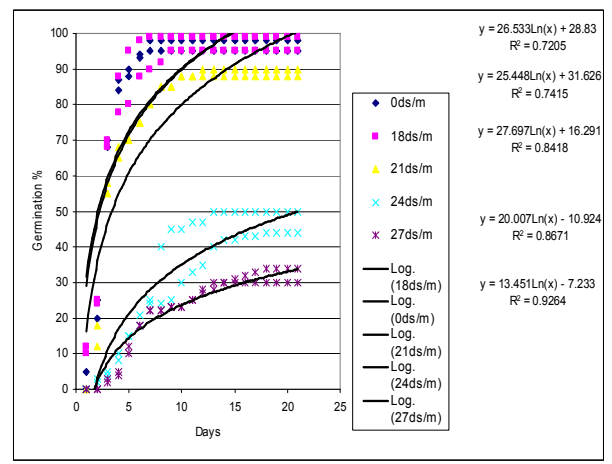

Pokkali

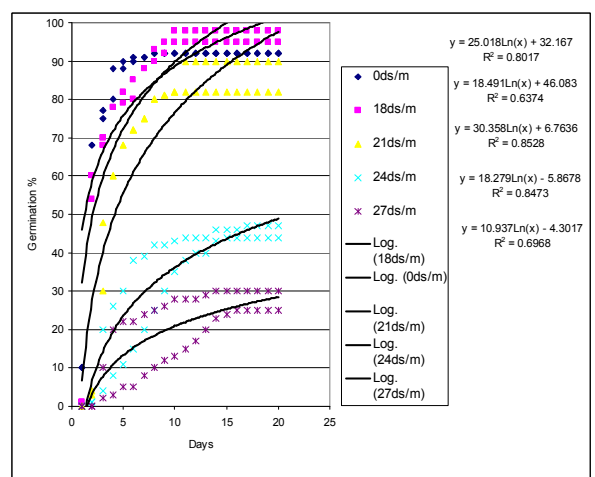

AT 401

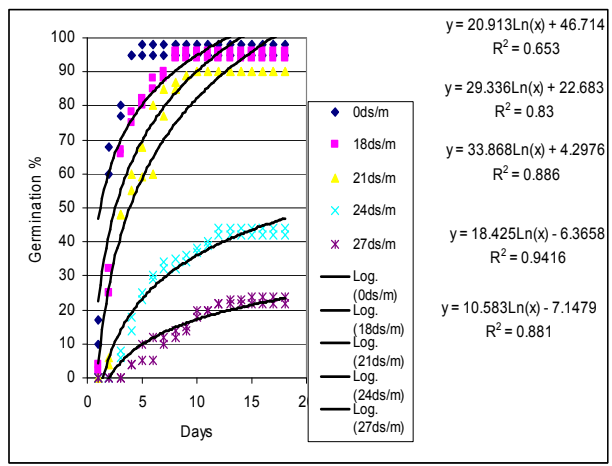

BW 400

Figure 02: Lin-log regression plots of salinity tolerant varieties

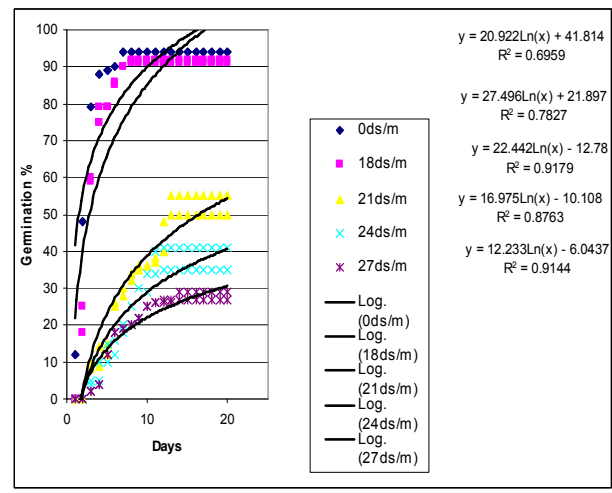

BG 94-1

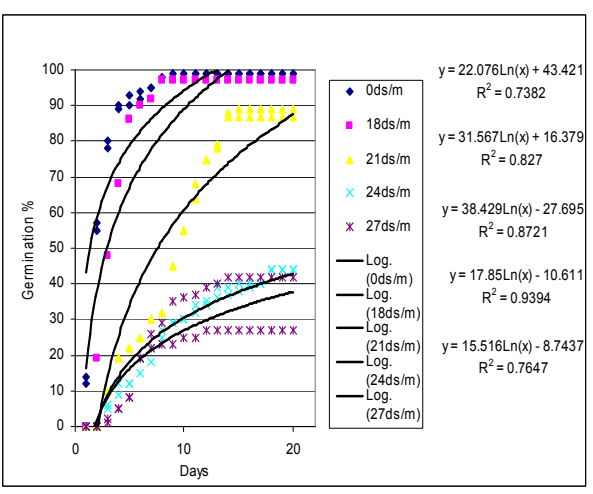

BG 350

Figure 03: Lin-log regression plots of salinity susceptible varieties

To evaluate the differences of seed germination of salinity susceptible and tolerant varieties during initial 6 days, simple linear regression analysis was performed. Simple linear regression plots of all salinity tolerant varieties are presented in figure 04 for all salt concentrations. A significant drop in germination percentage at $24 \mathrm{ds} / \mathrm{m}$ and $27 \mathrm{ds} / \mathrm{m}$ concentrations of salt for all salinity tolerant varieties was also observed. 


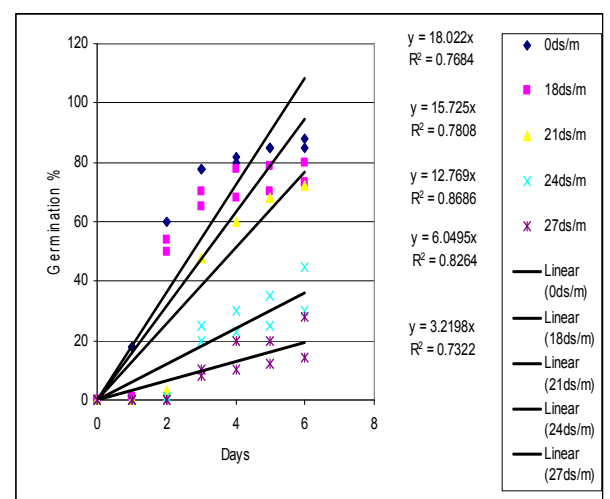

AT-95-26-4

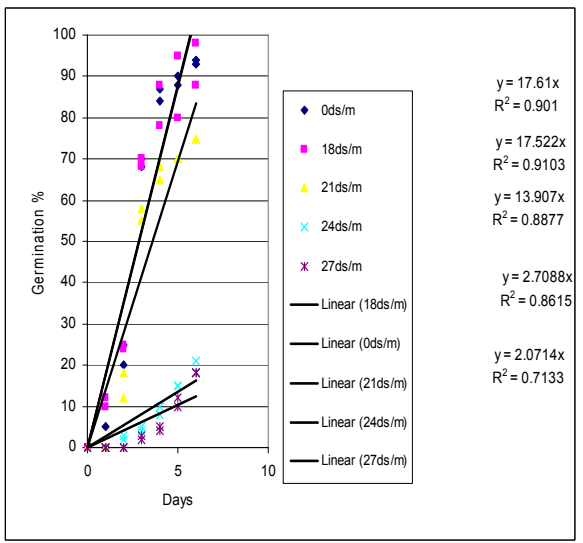

Pokkali

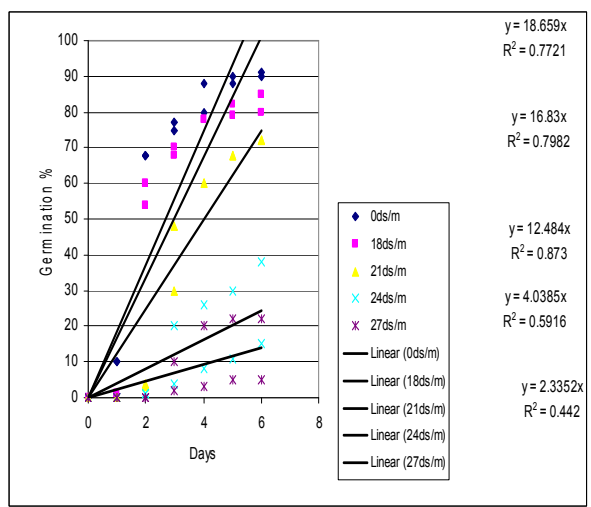

AT 401

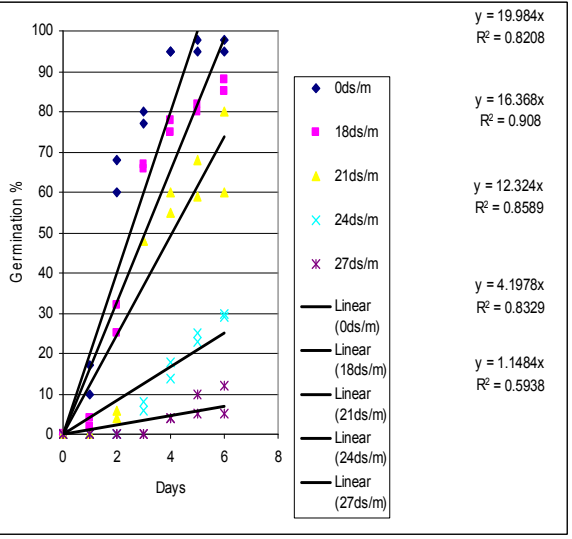

BW 400

Figure 04: Linear regression plots of salinity tolerant varieties

In figure 05 simple linear regression plots for salinity susceptible varieties are presented. A significant drop in germination percentage at $21 \mathrm{ds} / \mathrm{m} 24$ $\mathrm{ds} / \mathrm{m}$ and $27 \mathrm{ds} / \mathrm{m}$ salt concentration was obvious in all salt susceptible varieties. Unlike salinity tolerant varieties, these two susceptible verities showed a considerable drop in germination at $21 \mathrm{ds} / \mathrm{m}$ concentration of salt. Therefore, it was clear that the germination behavior at $21 \mathrm{ds} / \mathrm{m}$ salt concentration gave promising clue to differentiate salinity tolerant and susceptible varieties. Therefore, it was fair enough to count seed germination until $6^{\text {th }}$ day only to get different results of germination between salt tolerance and susceptible varieties. 


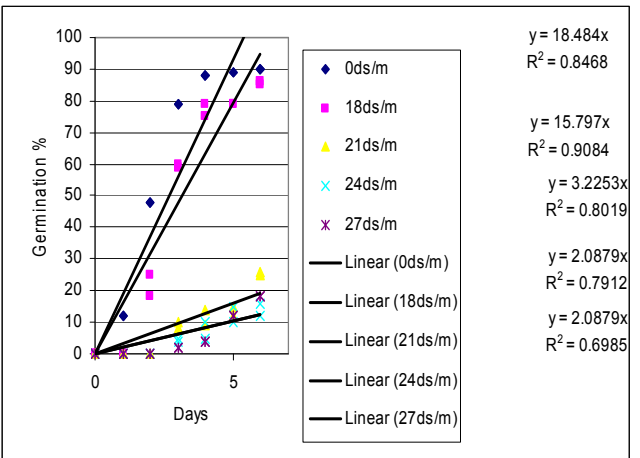

BG 94-1

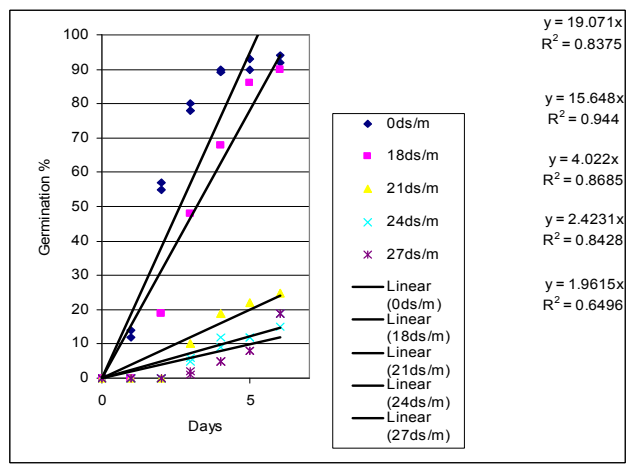

BG 350

Figure 05: Linear regression plots of salinity susceptible varieties

The resistance of BG 352 for salinity under different soil salt concentrations is still not known. The germination rate of BG 352 under different salt concentration levels is shown in figure 06. It showed a better germination percentage at $0 \mathrm{ds} / \mathrm{m} \quad 18 \mathrm{ds} / \mathrm{m}$ and $21 \mathrm{ds} / \mathrm{m}$ salt concentration levels while it was low at $24 \mathrm{ds} / \mathrm{m}$ and $27 \mathrm{ds} / \mathrm{m}$ salt concentration levels. This behavior was very much similar to the behavior observed in salinity tolerant varieties.

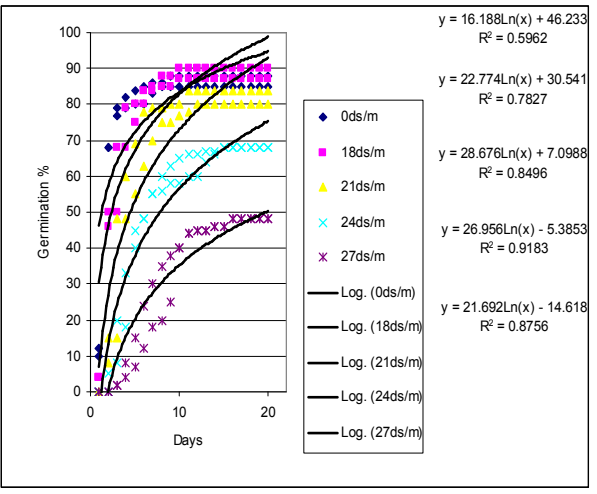

Lin-log regression plots

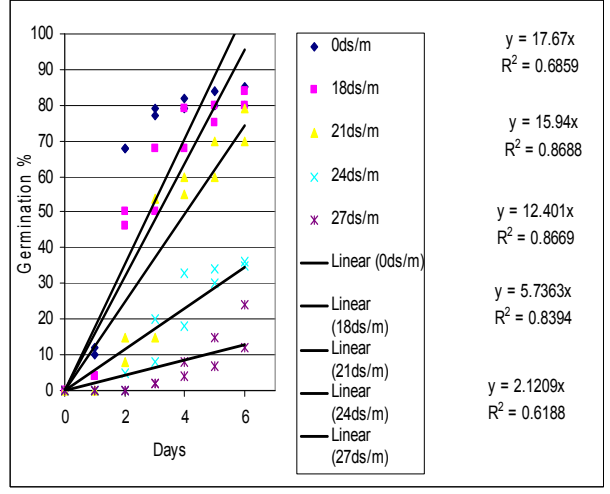

Linear regression plots

Figure 06: Germination behavior of BG 352 at different salt concentrations 
Table 02: Liner regression analysis and 95\% Prediction interval for salinity tolerant and susceptible varieties

\begin{tabular}{|c|c|c|c|c|c|c|c|c|}
\hline \multirow[t]{2}{*}{ Variety } & \multirow{2}{*}{$\begin{array}{l}\text { Respons } \\
\text { e for } \\
\text { salinity }\end{array}$} & \multirow{2}{*}{$\begin{array}{l}\text { Salinity } \\
\text { Level } \\
(\mathrm{ds} / \mathrm{m})\end{array}$} & \multicolumn{5}{|c|}{ Regression Analysis } & \multirow{2}{*}{$\begin{array}{l}\text { 95\%Prediction } \\
\text { Interval at } 6^{\text {th }} \\
\text { day (Lower } \\
\text { limit, Upper } \\
\text { Limit) }\end{array}$} \\
\hline & & & $\begin{array}{l}\text { Regression } \\
\text { Coefficient }\end{array}$ & Std. dev & $\mathrm{t}$ & Prob. & $r^{2}$ & \\
\hline AT-95- & Tolerant & 0 & 18.0 & 1.027 & 14.93 & 0.000 & 0.77 & $69.62,146.64$ \\
\hline \multirow[t]{2}{*}{$26-4$} & & 21 & 12.8 & 0.8540 & 14.78 & 0.000 & 0.87 & $52.05,104.18$ \\
\hline & & 24 & 6.05 & 0.4911 & 12.32 & 0.000 & 0.83 & $20.63,49.96$ \\
\hline \multirow[t]{3}{*}{ AT 401} & Tolerant & 0 & 18.7 & 1.301 & 14.34 & 0.000 & 0.77 & $70.45,153.46$ \\
\hline & & 21 & 12.5 & 0.8433 & 14.8 & 0.000 & 0.87 & $48.00,101.81$ \\
\hline & & 24 & 4.04 & 0.6098 & 6.62 & 0.000 & 0.59 & $4.78, \quad 43.69$ \\
\hline \multirow[t]{3}{*}{ Pokkali } & Tolerant & 0 & 17.6 & 0.9395 & 18.74 & 0.000 & 0.90 & $75.68,135.63$ \\
\hline & & 21 & 13.9 & 0.8116 & 17.14 & 0.000 & 0.89 & $57.55,109.33$ \\
\hline & & 24 & 2.71 & 0.2031 & 13.34 & 0.000 & 0.86 & $9.774,22.732$ \\
\hline \multirow[t]{3}{*}{ BW 400} & Tolerant & 0 & 20.0 & 1.228 & 16.27 & 0.000 & 0.82 & $80.71,159.09$ \\
\hline & & 21 & 12.3 & 0.8593 & 14.34 & 0.000 & 0.86 & $46.53,101.36$ \\
\hline & & 24 & 3.22 & 0.8113 & 13.51 & 0.000 & 0.83 & $8.56,21.35$ \\
\hline \multirow[t]{3}{*}{ BG 94-1 } & Suscepti & 0 & 18.5 & 1.074 & 17.21 & 0.000 & 0.85 & $76.63,145.17$ \\
\hline & ble & 18 & 15.8 & 0.8181 & 19.31 & 0.000 & 0.91 & $68.68,120.88$ \\
\hline & & 21 & 3.23 & 0.3034 & 10.63 & 0.000 & 0.81 & $9.67, \quad 29.03$ \\
\hline \multirow[t]{3}{*}{ BG 350} & Suscepti & 0 & 19.1 & 1.121 & 17.02 & 0.000 & 0.84 & $78.68,150.18$ \\
\hline & ble & 18 & 15.6 & 0.6513 & 24.03 & 0.000 & 0.94 & $73.11,114.67$ \\
\hline & & 21 & 4.02 & 0.2878 & 13.98 & 0.000 & 0.87 & $14.95, \quad 33.31$ \\
\hline \multirow[t]{3}{*}{ BG 352} & Unknow & 0 & 17.7 & 1.436 & 12.3 & 0.000 & 0.69 & $78.68,150.18$ \\
\hline & $\mathrm{n}$ & 21 & 12.4 & 0.8493 & 14.6 & 0.000 & 0.87 & $47.31,101.50$ \\
\hline & & 24 & 5.7 & 0.971 & 13.1 & 0.000 & 0.84 & $8.92,34.22$ \\
\hline
\end{tabular}

Table 02 presents the detailed results of linear regression models of salinity tolerant rice varieties at 0,21 and $24 \mathrm{ds} / \mathrm{m}$ and salinity susceptible varieties at $0,18,21 \mathrm{ds} / \mathrm{m}$. It was clearly seen that the response of salinity tolerant varieties at $0 \mathrm{ds} / \mathrm{m}$ to $21 \mathrm{ds} / \mathrm{m}$ at $6^{\text {th }}$ day after soaking in water overnight did not show any significant difference as the overlapping prediction intervals. But the remarkable drop in germination percentage at $24 \mathrm{ds} / \mathrm{m}$ (or above) was significantly different from the rest (21 $\mathrm{ds} / \mathrm{m}$ or below) as the prediction interval at $24 \mathrm{ds} / \mathrm{m}$ did not overlap with the rest. For an example, At-95-26-4 gave overlapping prediction intervals at $0 \mathrm{ds} / \mathrm{m}$ and $21 \mathrm{ds} / \mathrm{m}(69.62-146.64$ and $52.05-140.18$ respectively), which did not overlap with the prediction interval at $24 \mathrm{ds} / \mathrm{m}(20.63-$ 49.96). It was also noted that large slope coefficients at $0 \mathrm{ds} / \mathrm{m} 21 \mathrm{ds} / \mathrm{m}$ (18 and 12.8 respectively) represented faster rate of germination whereas smaller slope coefficient at $24 \mathrm{ds} / \mathrm{m}$ (6.05) emphasized slow rate of germination. These results were consistent with all resistant varieties. For salt susceptible varieties, germination percentages at $0 \mathrm{ds} / \mathrm{m}$ and $18 \mathrm{ds} / \mathrm{m}$ did not show any significant difference as prediction intervals were overlapping each other. In Bg 94-1 the prediction interval at $0 \mathrm{ds} / \mathrm{m}(76.63-$ 145.17) overlapped with the prediction interval at $18 \mathrm{ds} / \mathrm{m}(68.68-120.88)$. In $\mathrm{Bg} 350$ the prediction interval at 0 $\mathrm{ds} / \mathrm{m}(60.2$ - 151.84) overlapped with the prediction interval at $18 \mathrm{ds} / \mathrm{m}$ (73.11 - 114.67). But there were a significant drop in germination percentage at $21 \mathrm{ds} / \mathrm{m}$ in two susceptible varieties during initial 6 days compared to salinity tolerant varieties. $\mathrm{Bg} 352$ is still unknown variety for salinity tolerant. According to the results presented in table 02 it showed similar behavior as salinity tolerant variety. 


\section{CONCLUSION}

By comparison of germination percentages at $21 \mathrm{ds} / \mathrm{m}$ salt level, salinity tolerant and susceptible rice varieties could be distinguished conveniently, as drastic suppression of germination rate of susceptible varieties can be observed than the resistant varieties at this salt level. The detailed results of linear regression models of salinity tolerant rice varieties and salinity susceptible varieties was clearly shown that the response of salinity tolerant varieties differently behave than susceptible.
For resistant varieties the large slope coefficients at $0 \mathrm{ds} / \mathrm{m} 21 \mathrm{ds} / \mathrm{m}(18$ and 12.8 respectively) represented faster rate of germination whereas smaller slope coefficient at $24 \mathrm{ds} / \mathrm{m}$ (6.05) emphasized slow rate of germination. These results were consistent with all resistant varieties. For two salt susceptible varieties, there was a significant drop in germination percentage at $21 \mathrm{ds} / \mathrm{m}$ during initial 6 days compared to salinity tolerant varieties. Hence this can be used as a tool to distinguish susceptible and resistant rice varieties at the seedling stage within 6 days of germination.

\section{References}

Akbar,M. and F.N.Ponnamperuma, (1982). Saline soils of South and South East Asia as potential rice lands.Rice research strategies for the future. IRRI. Manila. Philippines. pp265-281.

Central Bank (2000). Central Bank annual report Colombo. Sri Lanka

Chandler, R.F.Jr (1979). Rice in the Tropics: A guide to the development of national programes. West view press. Colarado.

Chowdhury, M.A.M., and D.J.F.Bowling (1995). Arapid method for screening rice plants for salt tolerance. Tropical Agricultural research. Vol 7. PGIA. University of Peradeniya. Sri Lanka.

Gangodawila, C.D., (1990). Country report - Land Resources with problem soils in Sri Lanka. Problem soils in Sri Lanka. Problem soils of Asia and Pacific Regional office for Asia and the Pasific (RAPA) FAO.

Gangodawila, C.D., (1994). The collection and analyzing land degradation data in Sri Lanka. The collection and analysis of land degradation data. RAPA publication. Regional office for Asia and Pacific, food and agricultural Organization of the United Nation. pp215-225.

IRRI. (1975). Annual report 1974. Los Banos, Philippines. pp127 -130

IRRI. (1985). 25 years of partnership. IRRI. Manila. Philippines.

IRRI. (1989). Towards 2000 and beyond. IRRI. Manila. Philippines.

Jenings, P.R., W.R. Coffman., and H.E.Kauffman (1979). Rice Improvement. IRRI. Manila. Philippines. pp167-170.

Massoud, F.I., (1974). Salinity and Alkalinity as soil degradation hazards. FAO/UNEP expert consultation on soil degradation. FAO. Rome.

Pearson,G.A., A.D.Ayers., and D.L.Eberhard. (1996). Relative salt tolerance of rice during germination and early seedling development. Soil Science. 102, pp151156.

Ponnamperuma, F.N.(1977). Screening rice for tolerance to mineral stress. IRRI. Research paper series 6.Scardaci S.C, M.C. Shannon, S.R. Grattan, A.U.Eke,

S.R. Roberts, S.G.Smith and J.E.Hill. (2002). Water management practices can affect salinity in rice fields. California Agriculture 56 .pp184-188. 